\title{
ANÁLISE EXPERIMENTAL DA RESISTÊNCIA À FLEXÃO SIMPLES DE VIGAS DE AÇO TIPO "I" COMPOSTAS DE PERFIS LAMINADOS DOTADAS DE EMENDAS SOLDADAS
}

\author{
Experimental analysis of resistance to bending type "I" steel beams simple \\ composite profiles rolled provided amendments welded \\ Rone Sergio Freitas Borges ${ }^{1}$, Orlando Ferreira Gomes ${ }^{2}$
}

Recebido em 22 de setembro de 2015; recebido para revisão em 03 de novembro de 2015; aceito em 08 de dezembro de 2015; disponível on-line em 02 de fevereiro de 2016.

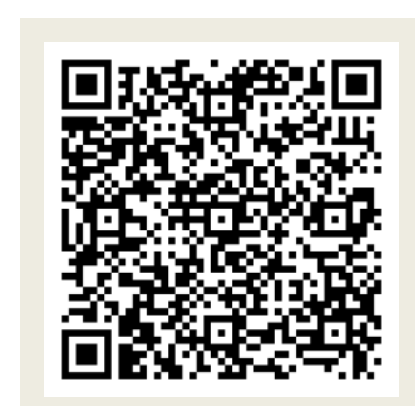

\author{
PALAVRAS CHAVE: \\ Viga; \\ Aço; \\ Ligações soldadas; \\ Ligações parafusadas; \\ Perfil laminado; \\ Flexão simples;
}

KEYWORDS:

Beam;

Steel;

Welded joints;

Bolted connections;

Laminate profile;

Simple bending

\footnotetext{
* Contato com os autores:

${ }^{1}$ e-mail : rsergiofb@gmail.com (R. S. F. Borges)

Professor Me. do Instituto Federal de Goiás - (IFG)

${ }^{2}$ e-mail : orlandoferreirag0@gmail.com (O. F. Gomes)

Professor Titular da Escola de Engenharia Civil e Ambiental - (EECA-UFG)
} solicitados. resisted the efforts required.
RESUMO: Este artigo apresenta o estudo experimental da capacidade resistente de vigas bi apoiadas em aço constituídas de perfis laminados de seção I do tipo W 250 x 22,3 ASTM A572 grau 50 laminados de abas paralelas com dois eixos de simetria, sendo dotadas de emendas com soldas de penetração total do tipo MIG (Metal Inert Gas). Foram ensaiadas sete vigas com comprimento de $3000 \mathrm{~mm}$, sendo uma viga de referência. Nas seis vigas restantes foram confeccionadas emendas em diferentes posições variando a quantidade de emendas. Além disso, faz-se uma comparação com o comportamento de vigas com emendas parafusadas estudadas por Pereira (2014), no qual utilizou vigas com emendas nas mesmas disposições das utilizadas neste trabalho, mas com parafusos ASTM A325 e diâmetro de $19 \mathrm{~mm}$. Todos os modelos foram submetidos a esforços de flexão simples até à ruptura, no qual foram medidos os deslocamentos verticais, deslocamentos relativos à torção e as deformações específicas do aço. As ligações das vigas resistiram aos ensaios de flexão simples, não sendo constatada nenhuma ruptura nas soldas e nem nos parafusos. A principal contribuição deste trabalho foi mostrar que as vigas com ligações soldadas e parafusadas, com as especificações descritas neste trabalho, podem ser utilizadas como elementos estruturais, pois resistiram bem aos esforços

ABSTRACT: This paper presents the experimental study of bearing capacity of bi supported by steel beams made of rolled section I of type W $250 \times 22.3$ ASTM A572 grade 50 profiles rolled parallel tabs with two axes of symmetry, being endowed with amendments with full penetration welds of type MIG (Metal Inert Gas). Seven beams were tested with a length of $3000 \mathrm{~mm}$, with a reference beam. In the remaining six beams amendments were made in different positions varying the amount of amendments. Furthermore, it is a comparison with the behavior of beams with bolt seams studied by Pereira (2014), in which beams used with the same provisions of seams used in this work, but with ASTM A325 and screw diameter of $19 \mathrm{~mm}$. All models were subjected to simple bending stress at break, in which the vertical displacements were measured relative displacements and specific torsional deformations steel. The links of beams resisted the simple bending tests, not being detected no break in welds and even the screws. The main contribution of this work was to show that the beams with welded and bolted connections with the specifications described in this paper can be used as structural elements, as well 


\section{INTRODUÇÃO}

No Brasil, apesar da escassez de mão de obra qualificada, a utilização de estruturas metálicas nas edificações vem aumentando consideravelmente devido a alguns fatores, tais como a rapidez de execução, limpeza do canteiro de obras, baixo peso próprio se comparado com as estruturas de concreto armado, baixo desperdício de material etc. Para combater esse desperdício e para que se dê continuidade dos vãos é necessário a utilização das emendas, que podem ser soldadas ou parafusadas. A qualidade e segurança estrutural das emendas nos perfis laminados deve atender aos padrões exigidos pela NBR 8800 (ABNT, 2008) (Projeto de Estruturas de Aço e de Estruturas Mistas de Aço e Concreto de Edifícios). Esses perfis têm grande aplicabilidade em estruturas de grande porte e seu uso é crescente em estruturas com essas características.

Quando se realiza uma ligação entre dois membros estruturais em aço, que pode ser entre Viga-Viga, Viga-Pilar, Pilar-Pilar e Pilar-Fundação, é fundamental que essa ligação, em primeiro lugar, garanta a segurança da edificação. Os projetos estruturais devem seguir de maneira fiel as recomendações das normas sobre o assunto, pois estas recomendam uma resistência mínima das ligações como medidas de segurança. Daí a importância de realizar esse estudo, pois as ligações entre os elementos influem diretamente na segurança e na capacidade portante da edificação.

\section{OBJETIVOS}

Este trabalho teve como objetivo analisar a capacidade resistente de vigas bi apoiadas em aço, constituídas de perfis laminados de seção I do tipo W $250 \times$ 22,3 ASTM A572 grau 50 laminados de abas paralelas com dois eixos de simetria, sendo dotadas de emendas com soldas de penetração total, sendo estes modelos solicitados por esforços de flexão simples.

Além disso, verificar ao executar as emendas com soldas ao longo do comprimento da viga, qual o efeito que tais emendas provocarão na resistência final à flexão, bem como na questão dos estados limites de flambagem lateral com torção e flambagem local da mesa e da alma do perfil.

Por fim, também, comparar os resultados obtidos nos ensaios das vigas com ligações soldadas deste trabalho, com os obtidos das vigas com ligações parafusadas, realizados por Pereira (2014), no qual utiliza perfis laminados com as mesmas características dos perfis utilizados neste trabalho, considerando as particularidades de cada pesquisa.

\section{REVISÃO BIBLIOGRÁFICA}

Vários trabalhos foram desenvolvidos com objetivo de analisar a influência das ligações no comportamento de vigas metálicas submetidas aos esforços de flexão simples. Dentre alguns pesquisadores, podem ser citados CARDOSO (2003), SILVA (2007), ALMEIDA (2009), VIEIRA (2010) e PEREIRA (2014).

Cardoso (2003), realizou o estudo do comportamento de vigas metálicas com seção composta "caixa", constituída de perfis formados a frio, com emendas soldadas (eletrodo revestido), submetidas a flexão simples. Verificou-se que nas vigas soldadas ocorreu um aumento na rigidez, diminuição na flecha máxima e na ductilidade.

Silva (2007), realizou o estudo do comportamento de vigas metálicas em perfil soldado tipo "I", com emendas soldadas (eletrodo revestido), submetidas à flexão simples. Verificou-se que nas vigas soldadas ocorreu um aumento na resistência e uma diminuição na flecha máxima.

Almeida (2009), realizou uma análise experimental de vigas de perfis formados a frio compostas pela junção de dois perfis $U$ enrijecidos, com emendas soldadas (eletrodo revestido), submetidas à flexão simples. Verificou-se que a quantidade de emendas 1, 2 ou 3, não influenciou expressivamente na resistência das vigas.

Vieira (2010), realizou uma análise experimental de vigas de seção "I" compostas de perfis formados a frio com emendas soldadas (MIG), submetidas à flexão simples. Verificou-se que a presença da solda, tão pouco o seu 
posicionamento, influenciaram de forma significativa na resistência das vigas.

Pereira (2014), realizou um estudo que teve por objetivo analisar a capacidade resistente a flexão simples de vigas bi apoiadas em aço com emendas parafusadas. Os aços empregados na fabricação das vigas estudadas foram: perfil Gerdau Aço Minas laminado com abas paralelas do tipo W 250 x 22,3 ASTM-A572, chapa Gerdau Aço Minas laminada do tipo ASTM-A36 e parafusos de alta resistência ASTM-A325 3/4×2", sendo utilizada a ligação por contato entre parafusos, perfil e chapa de ligação. Foram confeccionadas oito vigas com $3000 \mathrm{~mm}$ de comprimento variando a posição das ligações, a mesma utilizada nessa pesquisa de acordo com a Tabela 2. As vigas não tinham nenhum tipo de contenção lateral nos apoios. Verificou-se que as vigas com ligações parafusadas apresentaram máximos deslocamentos verticais três vezes maior que as vigas sem ligações, devido a acomodação ocorrida pela aplicação da carga entre parafusos, chapas de ligações e perfis, comprovando uma maior rigidez das vigas sem ligações. Não ocorreu rupturas nos parafusos, nem nas chapas de ligação e nenhuma viga rompeu por escoamento do aço. A quantidade de ligações não foi um fator de colapso das vigas. Ele concluiu que as vigas com ligações parafusadas são resistentes e, por isso, podem ser utilizadas por projetistas da área de estrutura metálica como mais uma opção.

\section{METODOLOGIA}

Este item descreve a metodologia dos ensaios de caracterização do aço, caracterização da solda e ensaios das vigas metálicas submetidas à flexão simples. Os perfis laminados utilizados na confecção das vigas ensaiadas foram obtidos mediante o corte em peças de 3000 mm de comprimento. Os ensaios de caracterização do aço e caracterização da solda foram realizados no Laboratório de Resistência dos Materiais da Pontifícia Universidade Católica de Goiás (PUC-GO). Os ensaios das vigas submetidas à flexão simples foram realizados no Laboratório de Estruturas da Escola de Engenharia Civil e
Ambiental da Universidade Federal de Goiás (EECA/UFG). Os materiais empregados na fabricação das vigas estudadas neste trabalho foram: perfil Gerdau Aço Minas laminado com abas paralelas do tipo W $250 \times 22,3$ ASTM-A572 com especificações de acordo com a norma ABNT NBR 7007 (ABNT, 2011) (Aço-carbono e micro ligados para barras e perfis laminados a quente para uso estrutural), chapa de aço ASTM A-36 e ligações soldadas com solda MIG (Metal Inert Gas) de penetração total.

\subsection{CARACTERIZAÇÃO DO AÇO E DA SOLDA}

Para determinação das propriedades mecânicas do aço e da solda utilizada, foram retirados corpos de prova das chapas das mesas e da alma do perfil; corpos de prova da chapa da contenção lateral e enrijecedor. Todos os corpos de prova foram submetidos aos ensaios de tração. Nesses ensaios foram obtidos os valores da resistência ao escoamento do aço $\left(f_{y}\right)$, da resistência à ruptura do aço à tração $\left(f_{u}\right)$ e o alongamento dos corpos de prova após os ensaios $(\Delta /)$. Os procedimentos utilizados nos ensaios à tração estão prescritos na norma NBR ISO 6892-1 (ABNT, 2013) (Materiais metálicos: Ensaio de tração) e os resultados são apresentados no item 5. O alongamento foi medido sobre a base de medida de $80 \mathrm{~mm}$. A nomenclatura utilizada para identificação dos corpos de prova, está indicada na Tabela 1.

\begin{tabular}{|c|c|c|}
\hline \multicolumn{3}{|c|}{$\begin{array}{l}\text { TABELA 1: Nomenclatura dos corpos de prova para } \\
\text { caracterização do aço e da solda. }\end{array}$} \\
\hline $\begin{array}{c}\text { Corpo de } \\
\text { prova }\end{array}$ & Quantidade & $\begin{array}{l}\text { Emenda } \\
\text { soldada }\end{array}$ \\
\hline CPA & 3 & Não \\
\hline CPMS & 3 & Não \\
\hline CPMI & 3 & Não \\
\hline CPCL & 3 & Não \\
\hline CPAE & 3 & Sim \\
\hline CPMSE & 3 & Sim \\
\hline CPMIE & 3 & Sim \\
\hline $\begin{array}{l}\text { CPA = Corpo de } \\
\text { CPMS = Corpo } d \\
C P M I=\text { Corpo de } \\
C P C L=\text { Corpo de } \\
\text { CPAE = Corpo de } \\
\text { CPMSE = Corpo } \\
\text { Soldada } \\
\text { CPMIE = Corpo } \\
\text { Soldada }\end{array}$ & $\begin{array}{l}\text { hapa da Alma } \\
\text { chapa da Mesa } \\
\text { chapa da Mesa I } \\
\text { chapa da Conten } \\
\text { chapa da Alma c } \\
\text { la chapa da Mesa } \\
\text { a chapa da Mesa }\end{array}$ & $\begin{array}{l}\text { e enrijecedor } \\
\text { a Soldada } \\
\text { m Em Emenda } \\
\text { mema }\end{array}$ \\
\hline
\end{tabular}


Os corpos de prova foram retirados de três chapas de aço antes da operação de montagem (aço virgem), sendo estas chapas com espessuras de 6,30 $\mathrm{mm}$ (chapa da contenção lateral e enrijecedor), 5,80 mm (chapa da alma) e $6,90 \mathrm{~mm}$ (chapa da mesa). As dimensões nominais para esses corpos de prova, soldados e não soldados, estão indicadas na Figura 1.

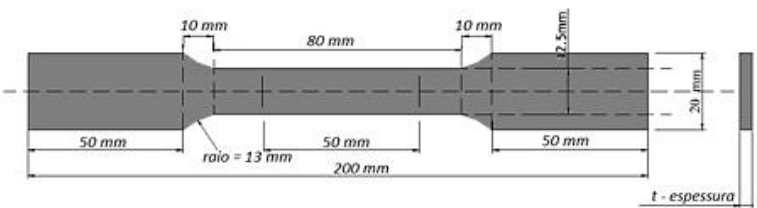

(a) Corpos de prova sem emendas

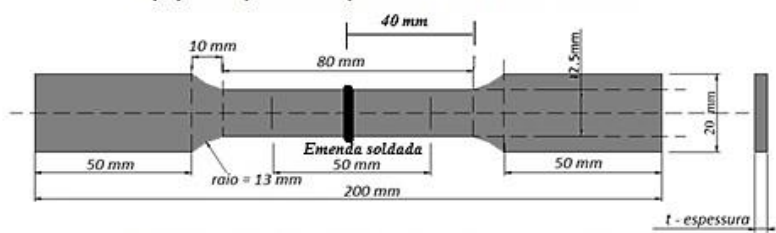

(b) Corpos de prova com emendas

FIGURA 1: Dimensões dos corpos de prova para ensaios de tração.

O processo de soldagem utilizado nas emendas dos corpos de prova foi o arco elétrico com gás de proteção (Gas Metal Arc Welding GMAW) também conhecido como soldagem MIG/MAG (MIG - Metal Inert Gas; MAG - Metal Active Gas). A solda utilizada nos corpos de prova foi a mesma que se utilizou na união das vigas e seguiu as especificações da American Society of Mechanical Engineers (ASME). O material de adição utilizado na soldagem do aço foi o arame de solda MIG das classes ASME AWS ER70S-6, diâmetro $1,2 \mathrm{~mm}$ e resistência à tração que chega a $480 \mathrm{MPa}$. Esse material de adição possui compatibilidade com o aço utilizado, segundo a Tabela 7 da NBR 8800 (ABNT, 2008). Nas extremidades das partes dos corpos de prova foram confeccionados chanfros em duplo $V$ com um ângulo do bisel de $45^{\circ}$ de forma que a solda fosse com penetração total (ver Figura 2).

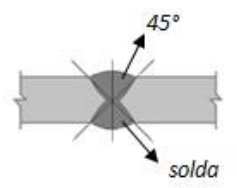

FIGURA 2: llustração da solda.

\subsection{CARACTERÍSTICAS DOS MODELOS ENSAIADOS}

Para o desenvolvimento desta pesquisa foram confeccionadas sete vigas com $3000 \mathrm{~mm}$ de comprimento constituídas de perfis Gerdau Aço Minas laminado com abas paralelas do tipo W 250 x 22,3 ASTM-A572 com altura de $250 \mathrm{~mm}$, espessura da chapa da alma de $5,8 \mathrm{~mm}$ e de espessura da chapa da mesa de $6,9 \mathrm{~mm}$. Em todas as vigas que continham ligações, foram utilizadas soldas do tipo MIG de penetração total com ângulo do bisel de $45^{\circ}$ (ver Figura 2). Com o objetivo de dificultar o deslocamento lateral, foram soldadas Contenções Laterais nas sete vigas, nas duas extremidades de cada viga, utilizando chapa de aço ASTM A-36 com espessura de 6,3 $\mathrm{mm}$, como mostra a Figura 3.

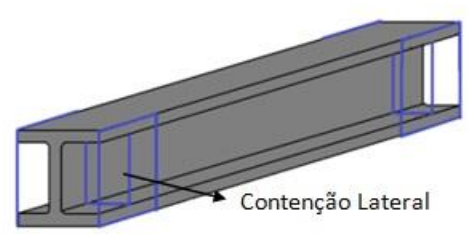

FIGURA 3: Detalhes e posicionamento da Contenção Lateral.

Para a soldagem das chapas foi utilizada solda de filete com perna do filete igual a $5 \mathrm{~mm}$, conforme a NBR 8800 (ABNT, 2008). A Figura 4 mostra as medidas, em milímetros, das chapas utilizadas na confecção das Contenções Laterais.

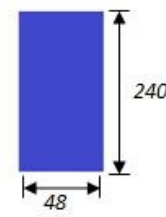

(a)

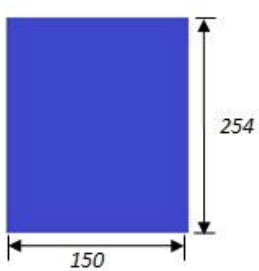

(b)
FIGURA 4: (a) Chapa interna (enrijecedor); (b) Chapa externa.

Para execução dos ensaios de flexão simples nas vigas deste estudo, primeiramente foi realizado a montagem das vigas que continham ligações, para tanto foi utilizado a máquina de solda MIG ESAB LAI 400 na realização das soldas e alimentador de arame ESAB MEF 30R. 
A nomenclatura dos modelos analisados e as disposições das emendas foi a mesma definida por Pereira (2014), como mostra a Tabela 2. A Figura 5 ilustra cada viga.

\begin{tabular}{ll}
\hline \multicolumn{2}{c}{ TABELA 2: Nomenclatura dos modelos ensaiados. } \\
\hline VREF & Viga de referência: sem emenda \\
\hline V1LD & $\begin{array}{l}\text { Viga com uma ligação soldada a } 1000 \mathrm{~mm} \\
\text { do apoio da direita }\end{array}$ \\
\hline V1LE & $\begin{array}{l}\text { Viga com uma ligação soldada a 1000 mm } \\
\text { do apoio da esquerda }\end{array}$ \\
\hline V1LME & $\begin{array}{l}\text { Viga com uma ligação soldada no meio do } \\
\text { vão e enrijecedores a } 750 \mathrm{~mm} \text { dos dois } \\
\text { apoios }\end{array}$ \\
\hline V1LM & $\begin{array}{l}\text { Viga com uma ligação soldada no meio do } \\
\text { vão e sem enrijecedores }\end{array}$ \\
\hline V2L & $\begin{array}{l}\text { Viga com duas ligações soldadas a 1000 } \\
\text { mm dos dois apoios }\end{array}$ \\
\hline V3L & $\begin{array}{l}\text { Viga com três ligações soldadas: uma no } \\
\text { meio do vão e duas a } 750 \text { mm dos dois } \\
\text { apoios }\end{array}$ \\
\hline
\end{tabular}

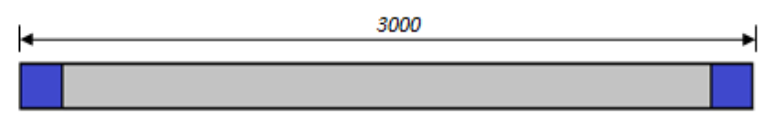

(a) Viga VREF

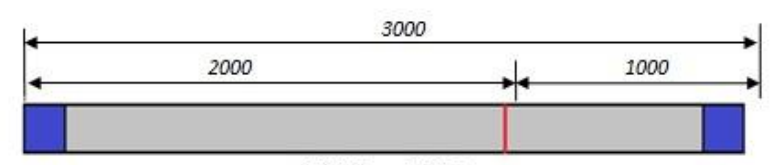

(b) Viga V1LD

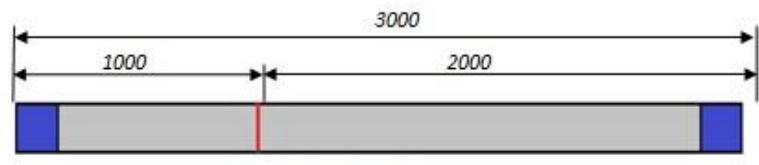

(c) Viga V1LE

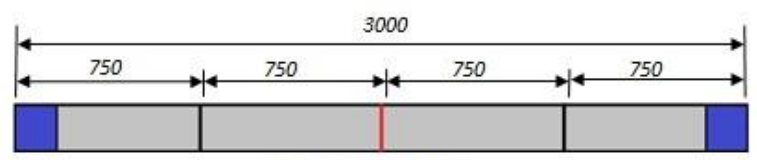

(d) Viga V1LME

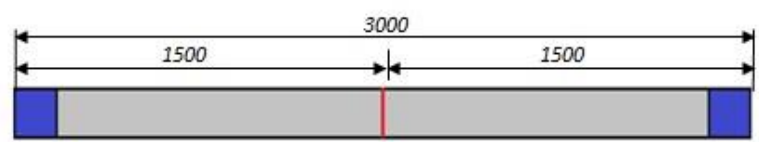

(e) Viga V1LM

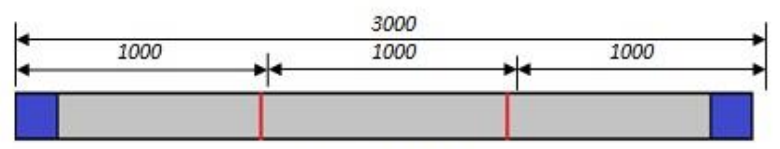

(f) Viga V2L

\begin{tabular}{|c|c|c|c|}
\hline \multicolumn{4}{|c|}{3000} \\
\hline 750 & 750 & 750 & 750 \\
\hline
\end{tabular}

(g) Viga V3L

FIGURA 5: llustrações dos modelos ensaiados.

\subsection{INSTRUMENTAÇÃO}

A instrumentação antecede a execução dos ensaios. Foram utilizados extensômetros de resistência elétrica (strain gages) para o aço da marca EXCEL para medir as deformações do aço. A operação de instalação dos extensômetros nas vigas seguiu as seguintes etapas: soldagem dos fios do tipo cabo eletrônico $\mathrm{CCl}$ nos terminais dos extensômetros ; preparação da superfície da viga utilizando lixa e limpeza da superfície com álcool isopropílico, condicionador e neutralizador ; colagem do extensômetro utilizando cola cianoacrilato, isolamento com fita para evitar contato dos terminais com as barras e aplicação da proteção mecânica com fita isolante. Em todas as vigas que tinham ligações, eles foram deslocados $20 \mathrm{~mm}$ à esquerda de cada ligação, nas mesas e almas dos perfis.

\subsection{ESQUEMA DE ENSAIO}

O esquema estático das vigas simula uma viga bi apoiada, onde cada viga ensaiada tinha um comprimento total de $3000 \mathrm{~mm}$, na qual foi deixada uma folga de $75 \mathrm{~mm}$ entre o eixo do apoio e a extremidade da viga, sendo assim, o vão livre entre os apoios foi de $2850 \mathrm{~mm}$. A Figura 6 apresenta um sistema esquematizado de ensaio das vigas.

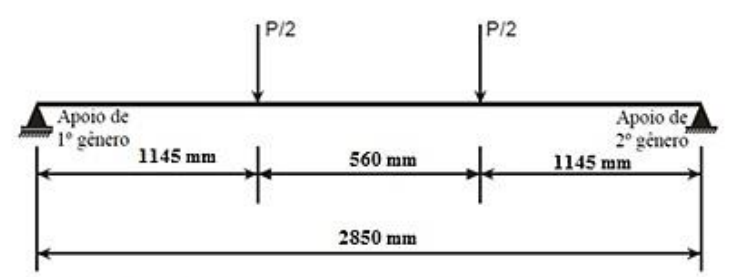

FIGURA 6: Esquema de aplicação das forças.

Foram utilizados aparelhos de apoio formados por chapas metálicas e cilindros de aço simulando os apoios de 1 으 e 2 o gênero. Para aplicação da carga concentrada foi utilizada uma viga de transição apoiada sobre a viga ensaiada, isto para obter uma divisão da intensidade da força $P$ aplicada em duas forças iguais a $P / 2$. O carregamento foi aplicado com a ajuda de atuador hidráulico da marca (Yellow Power) com capacidade de $500 \mathrm{kN}$, e sua intensidade foi 
verificada por uma célula de carga posicionada entre o atuador hidráulico e a viga de reação. Para leitura das deformações de todos os extensômetros foi utilizado o equipamento de coleta de dados AGILENT BenchLink Data Logger Modelo 34970A.

Após o posicionamento final da viga foram instalados relógios comparadores para medir os deslocamentos verticais. Foram utilizados relógios com precisão de $0,01 \mathrm{~mm}$ e leitura máxima de $50 \mathrm{~mm}$. Com o objetivo de verificar o deslocamento lateral da mesa superior e a rotação da seção transversal na viga foram instalados LVDTs (linear variable differential transformer) na alma da viga a $170 \mathrm{~mm}$ de cada extremidade

O método de montagem do ensaio foi desenvolvido para que todos os ensaios fossem padronizados sendo dividido na seguinte sequência de etapas: instalação dos aparelhos de apoio, posicionamento da viga, instalação dos aparelhos de apoio da viga de transmissão, posicionamento da viga de transmissão, posicionamento do atuador hidráulico, posicionamento da célula de carga, verificação do prumo; marcação e posicionamento dos aparelhos medidores. A Figura 7 ilustra todo o aparato experimental.

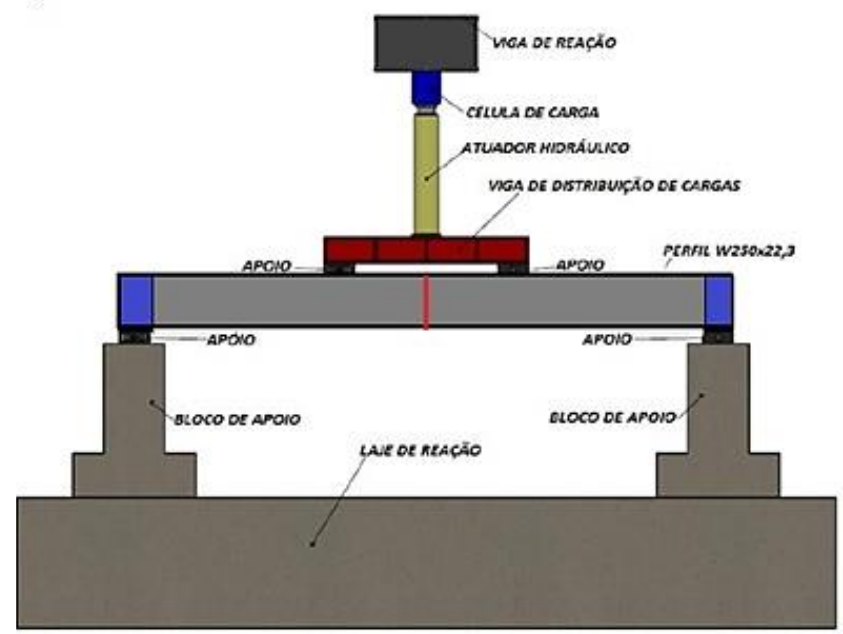

FIGURA 7: Ilustração do esquema montado para o ensaio dos modelos das vigas.

\section{RESULTADOS E DISCUSSÕES}

\subsection{CARACTERIZAÇÃO DO AÇO E DA SOLDA}

A Tabela 3 apresenta as propriedades mecânicas do aço do perfil ASTM-A572 grau 50, da chapa da contenção lateral e enrijecedor ASTM-A36 e do eletrodo de solda MIG utilizado.

\begin{tabular}{|c|c|c|c|c|}
\hline Especif. & $\begin{array}{c}\text { Equiv. } \\
\text { NBR } \\
7007: \\
2011\end{array}$ & $\begin{array}{c}\text { Lim. de } \\
\text { Escoam. } \\
\text { Mín. } \\
\text { (MPa) }\end{array}$ & $\begin{array}{l}\text { Lim. de } \\
\text { Resis. } \\
\text { Mín. } \\
\text { (MPa) }\end{array}$ & $\begin{array}{c}\text { Along. } \\
\text { Mín. após a } \\
\text { ruptura (\%) }\end{array}$ \\
\hline $\begin{array}{c}\text { ASTM } \\
\text { A36 }\end{array}$ & $\begin{array}{l}\text { MR } \\
250\end{array}$ & 250 & $\begin{array}{c}400- \\
560\end{array}$ & 23 \\
\hline $\begin{array}{c}\text { ASTM } \\
\text { A572 } \\
\text { Grau } 50\end{array}$ & $\begin{array}{l}\text { AR } \\
350\end{array}$ & 345 & $\begin{array}{l}450 \\
\text { mín. }\end{array}$ & 21 \\
\hline $\begin{array}{c}\text { ASME } \\
\text { AWS } \\
\text { ER70S-6 }\end{array}$ & ---- & 400 & 480 & 22 \\
\hline
\end{tabular}

FONTE: adaptada da NBR 7007 (ABNT, 2011) e AWS A5.18 (2005).

A Figura 8 apresenta o gráfico tensão versus deformação para os corpos de prova da mesa superior sem e com emenda soldada.

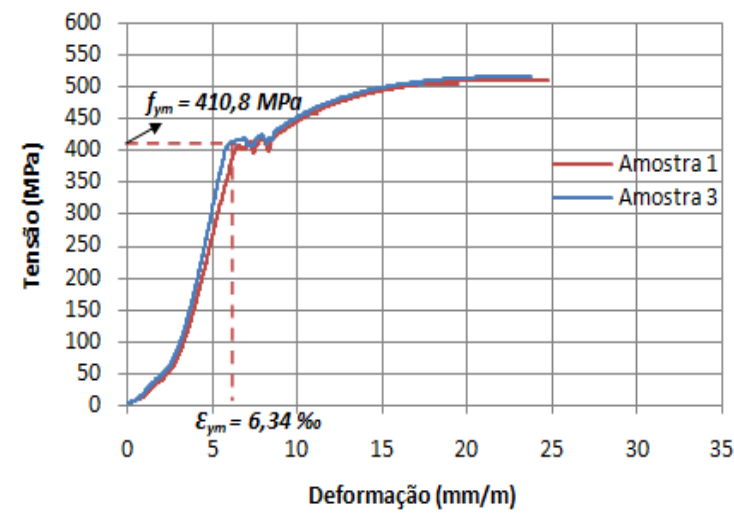

(a) CPMS

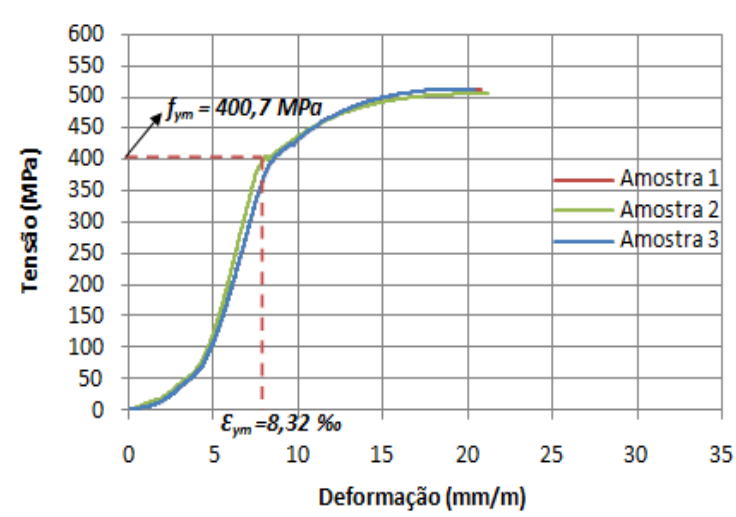

(b) CPMSE

FIGURA 8: Gráfico Tensão x Deformação para os corpos de prova da mesa superior. 


\subsection{CARGA E MODO DE RUPTURA}

A Tabela 5 apresenta os resultados das cargas últimas estimadas e as cargas últimas de ensaios, momentos fletores resistentes de ensaios, momentos fletores resistentes de cálculo segundo a NBR 8800 (ABNT, 2008) e os modos de falha das vigas com ligações soldadas deste trabalho e das vigas com ligações parafusadas realizada por Pereira (2014).

A Figura 9 (a) apresenta a viga V2L com ligação parafusada; a parte (b) apresenta a viga V2L com ligação soldada, ambas após o ensaio de flexão simples. Nessa figura estão indicados os modos de ruptura das duas vigas.

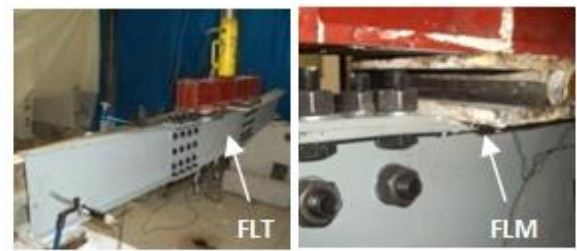

(a) Viga V2L com ligação parafusada

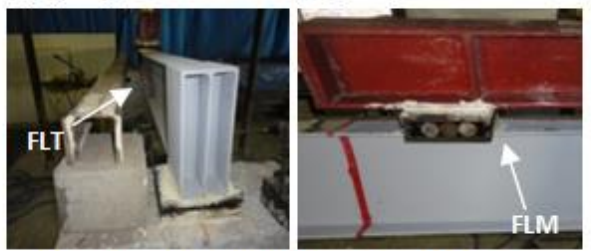

(b) Viga V2L com ligação soldada

FIGURA 9: Modos de ruptura das vigas V2L com ligações parafusadas e soldadas.

Os resultados da Tabela 5 mostram que todas as vigas com ligações parafusadas tiveram cargas últimas entre $86 \%$ e $99 \%$ da carga estimada de cálculo. O fato das vigas com ligações parafusadas resistirem menos do que o estimado, foi devido a ausência de contenção lateral nos apoios, pois a viga de referência que tinha contenção lateral teve uma carga de ruptura $16 \%$ maior em comparação com a viga de referência que não tinha. As posições em que foram soldados os enrijecedores não influenciaram no aumento das cargas de rupturas das vigas V1LME. As vigas com uma ligação soldada, apresentaram cargas de ruptura entre 0 e $19 \%$ maiores que a carga estimada de cálculo. As vigas com duas (V2L) e três (V3L) ligações soldadas, apresentaram cargas últimas menores que o estimado, com $84 \%$ e $92 \%$ da carga estimada, respectivamente. A não coplanaridade na região da solda (ver Figura 10), pode ser uma possível explicação para esse fato, devido a instabilidade criada e que pode ter acentuado à medida que foi aumentando a carga, provocando o colapso antes do esperado. Mas é preciso realizar uma investigação mais profunda sobre esse fato. Os momentos de ensaio das vigas V2L e V3L soldadas, foram inferiores aos momentos resistentes de cálculo para a FLM, mas mesmo assim, ocorreu FLM. Fato que pode ser explicado pela concentração de tensão ocorrida na mesa superior, nas duas áreas de aplicação da carga.

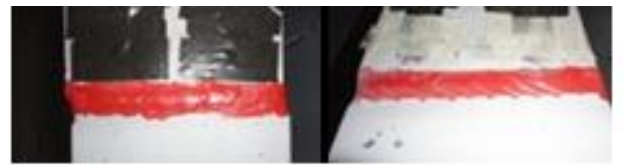

FIGURA 10: Região de não coplanaridade nas vigas V2L e V3L.

TABELA 5: Cargas últimas, momentos fletores resistentes e modos de falha das vigas com ligações parafusadas e soldadas.

\begin{tabular}{|c|c|c|c|c|c|c|c|c|c|c|c|}
\hline \multirow[t]{2}{*}{ Viga } & \multirow{2}{*}{$\begin{array}{l}P_{\mathrm{u} \text { est. }} \\
(\mathrm{kN})\end{array}$} & \multicolumn{2}{|c|}{$P_{u}(k N)$} & \multirow{2}{*}{$\frac{\mathbf{P}_{\mathrm{u} \text { Paraf. }}}{\mathbf{P}_{\mathrm{u} \text { Sold. }}}$} & \multicolumn{2}{|c|}{$M_{\text {ensaio }}(k N . m)$} & \multirow{2}{*}{$\begin{array}{c}M_{\text {RdFLA }} \\
\text { (kN.m) }\end{array}$} & \multirow{2}{*}{$\begin{array}{c}\mathrm{M}_{\mathrm{Rd}} \mathrm{FLM} \\
\text { (kN.m) }\end{array}$} & \multirow{2}{*}{$\begin{array}{l}M_{\text {Rd }} F L T \\
\text { (kN.m) }\end{array}$} & \multicolumn{2}{|c|}{ Modos de falha } \\
\hline & & Paraf. & Sold. & & Paraf. & Sold. & & & & Paraf. & Sold. \\
\hline VREF* & 146,7 & 135,0 & 160,0 & 0,84 & 77,3 & 91,6 & 84,0 & 84,0 & 49,2 & FLM/FLT & FLM/FLT \\
\hline V1LM & 146,7 & 135,0 & 166,0 & 0,81 & 77,3 & 95,0 & 84,0 & 84,0 & 49,2 & FLM/FLT & FLM/FLT \\
\hline V1LME & 146,7 & 133,5 & 160,0 & 0,83 & 76,4 & 91,6 & 84,0 & 84,0 & 49,2 & FLM/FLT & FLM/FLT \\
\hline V1LD & 146,7 & 138,0 & 163,0 & 0,85 & 79,0 & 93,3 & 84,0 & 84,0 & 49,2 & FLM/FLT & FLM/FLT \\
\hline V1LE & 146,7 & 140,0 & 175,0 & 0,80 & 80,1 & 100,2 & 84,0 & 84,0 & 49,2 & FLM/FLT & FLM/FLT \\
\hline V2L & 146,7 & 145,2 & 123,0 & 1,18 & 83,1 & 70,4 & 84,0 & 84,0 & 49,2 & FLM/FLT & FLM/FLT \\
\hline V3L & 146,7 & 126,4 & 135,0 & 0,94 & 72,4 & 77,3 & 84,0 & 84,0 & 49,2 & FLM/FLT & FLM/FLT \\
\hline
\end{tabular}

$\mathrm{P}_{\mathrm{u}}=$ Carga última de ensaio; $\mathrm{P}_{\mathrm{u} \text { est. }}$ = Carga última estimada de cálculo para o $\mathrm{M}_{\mathrm{Rd}}$ FLM, segundo o anexo G da ABNT NBR 8800:2008

$M_{\text {ensaio }}=$ Momento fletor resistente de cálculo em relação aos ensaios

$M_{R d}$ FLA , $M_{R d}$ FLM e $M_{R d}$ FLT = Momento fletor resistente de cálculo segundo o anexo G da NBR 8800:2008, para a FLA, FLM e FLT, respectivamente

FLM = Flambagem Local da Mesa; FLA = Flambagem Local da Alma; FLT = Flambagem Lateral com Torção

* Apesar de estarem posicionadas nas colunas de vigas parafusadas e soldadas, essas vigas não tem emendas. 


\subsection{DESLOCAMENTOS VERTICAIS MÁXIMOS}

A Figura 11 apresenta 0 posicionamento dos relógios em todas as vigas e os deslocamentos verticais da viga V1LM com ligação soldada. Os maiores deslocamentos verticais foram registrados no relógio $\mathrm{R} 3$, em todas as vigas com ligações soldadas. Já nas vigas com ligações parafusadas, ocorreram variações das posições dos deslocamentos verticais máximos. A Tabela 6 traz os resultados dos deslocamentos máximos para o estado limite de serviço (L/350 para viga de piso), conforme o anexo C da NBR 8800 (ABNT, 2008); da Resistência dos Materiais, determinou-se o deslocamento teórico de cálculo, segundo a Equação 4, para os deslocamentos verticais máximos que não ocorreram no meio do vão e segundo a Equação 5 para os deslocamentos verticais máximos que ocorreram no meio do vão; apresenta também o deslocamento máximo obtido nos ensaios. O cálculo da deflexão (deslocamento) máxima teórica de cálculo é desenvolvido abaixo:

$\frac{d v_{1}}{d x_{1}}=\frac{P}{2 E I}\left(x_{1}^{2}+a^{2}-a L\right)$

$\left.\frac{d v_{1}}{d x_{1}}\right|_{x=0}=\frac{P a(a-L)}{2 E I}$

$v_{1=\frac{P x_{1}}{6 E I}}\left[x_{1}^{2}+3 a(a-L)\right]$

$v_{2=\frac{P a}{6 E I}}\left[3 x(x-L)+a^{2}\right]$

$v_{\text {máx }}=\left.v_{2}\right|_{x=\frac{L}{2}}=\frac{P a}{24 E I}\left(4 a^{2}-3 L^{2}\right)$

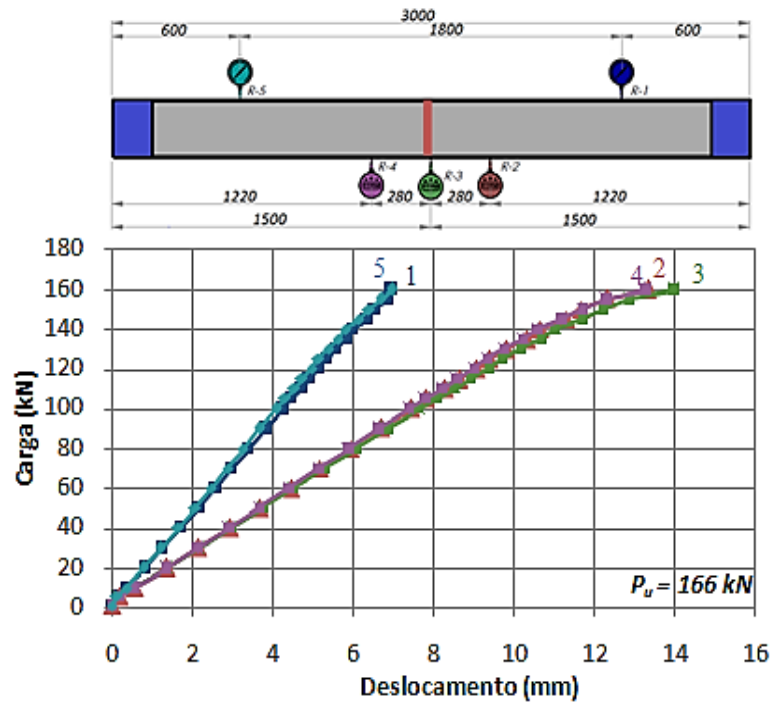

FIGURA 11: Deslocamentos verticais da viga V1LM soldada.

A Figura 12 apresenta os deslocamentos verticais máximos de ensaios das vigas com ligações soldadas e parafusadas.

Para ter uma comparação mais precisa do deslocamento vertical de ensaio em relação a uma mesma carga das vigas com ligações soldadas e parafusadas, foi traçado o gráfico do deslocamento vertical para a carga de 120 kN em função do comprimento para todas as vigas, como mostra a Figura 13. Para essa carga, os deslocamentos verticais das vigas com ligações parafusadas foram superiores aos das vigas com ligações soldadas, o que comprova uma maior rigidez das ligações soldadas em relação as ligações parafusadas. Esse fato pode ser explicado, devido a acomodação ocorrida entre perfil, chapa de ligação e parafusos, no momento do ensaio.

\begin{tabular}{|c|c|c|c|c|c|c|c|c|c|c|}
\hline \multirow[t]{2}{*}{ Viga } & \multicolumn{2}{|c|}{$P_{u}(k N)$} & \multirow{2}{*}{$\begin{array}{c}\Delta_{\text {máximo }} \\
(\mathrm{mm})\end{array}$} & \multicolumn{2}{|c|}{$\Delta_{\text {teórico }}(\mathrm{mm})$} & \multicolumn{2}{|c|}{$\Delta_{\text {ensaio }}(\mathrm{mm})$} & \multirow{2}{*}{$\frac{\Delta_{\text {ensaio Paraf. }}}{\Delta_{\text {ensaio Sold. }}}$} & \multicolumn{2}{|c|}{ Relógio } \\
\hline & Paraf. & Sold. & & Paraf. & Sold. & Paraf. & Sold. & & Paraf. & Sold. \\
\hline VREF* & 135,0 & 160,0 & 8,57 & 10,5 & 12,4 & 10,6 & 12,6 & 0,84 & R3 & R3 \\
\hline V1LM & 135,0 & 166,0 & 8,57 & 10,5 & 12,8 & 44,0 & 13,9 & 3,15 & R3 & R3 \\
\hline V1LME & 133,5 & 160,0 & 8,57 & 10,4 & 12,4 & 39,3 & 14,3 & 2,75 & R3 & R3 \\
\hline V1LD & 138,0 & 163,0 & 8,57 & 9,9 & 12,6 & 28,3 & 13,2 & 2,13 & $\mathrm{R} 2$ & R3 \\
\hline V1LE & 140,0 & 175,0 & 8,57 & 10,6 & 13,5 & 32,5 & 14,8 & 2,19 & R4 & R3 \\
\hline V2L & 145,2 & 123,0 & 8,57 & 11,0 & 9,3 & 46,2 & 9,7 & 4,72 & $\mathrm{R} 2$ & R3 \\
\hline V3L & 126,4 & 135,0 & 8,57 & 9,8 & 10,4 & 50,6 & 12,0 & 4,18 & R3 & R3 \\
\hline $\begin{array}{l}\mathrm{Pu}_{\mathrm{u}}=\text { Carga } \\
\Delta_{\text {máximo }}=\mathrm{De} \\
\Delta_{\text {teórico }}=\mathrm{De} \\
\text { Relógio }=\mathrm{R}\end{array}$ & $\begin{array}{l}\text { a de ens: } \\
\text { amento n } \\
\text { mento te } \\
\text { o que re }\end{array}$ & $\begin{array}{l}\text { no pe } \\
\text { o de c } \\
\text { ou o v }\end{array}$ & ; $\Delta_{\text {ensaio }}=$ & ocamen & iximo & $\begin{array}{l}\text { iso) } \\
\text { saio }\end{array}$ & & & & \\
\hline
\end{tabular}




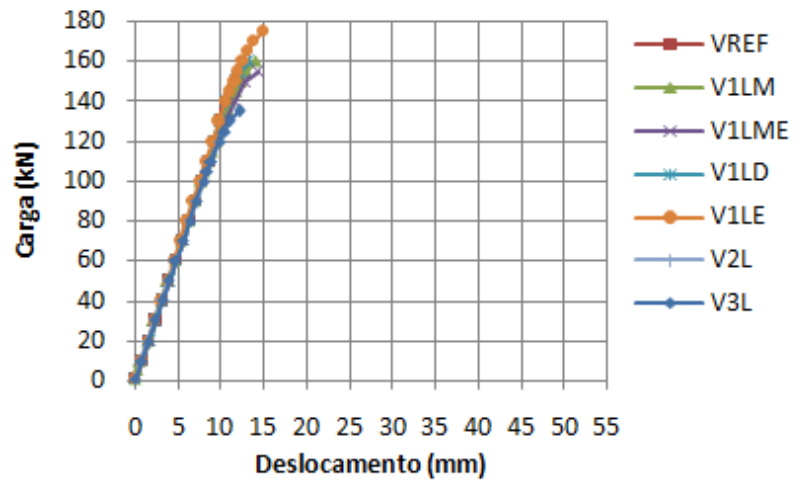

(a) Vigas com ligações soldadas

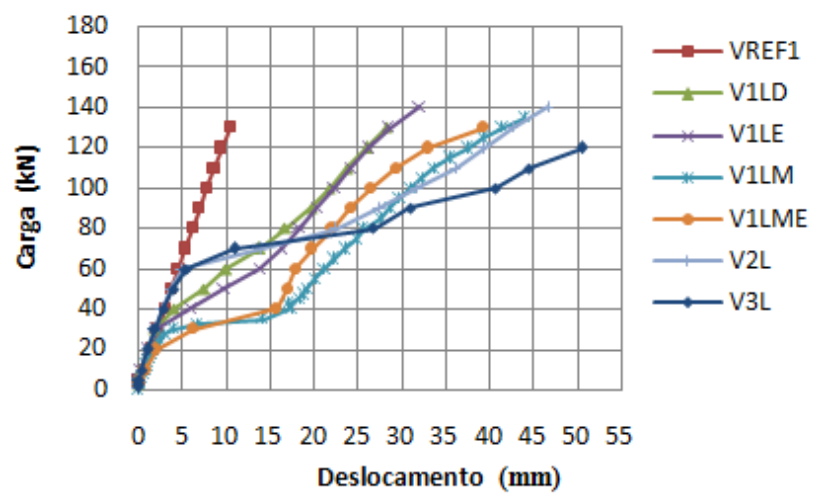

(b) Vigas com ligações parafusadas

FIGURA 12: Deslocamentos verticais máximos de ensaio.

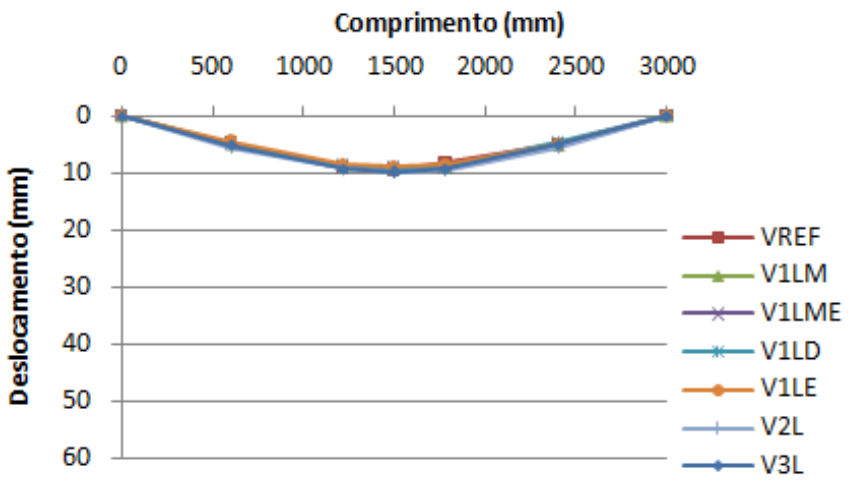

(a) Vigas com ligações soldadas

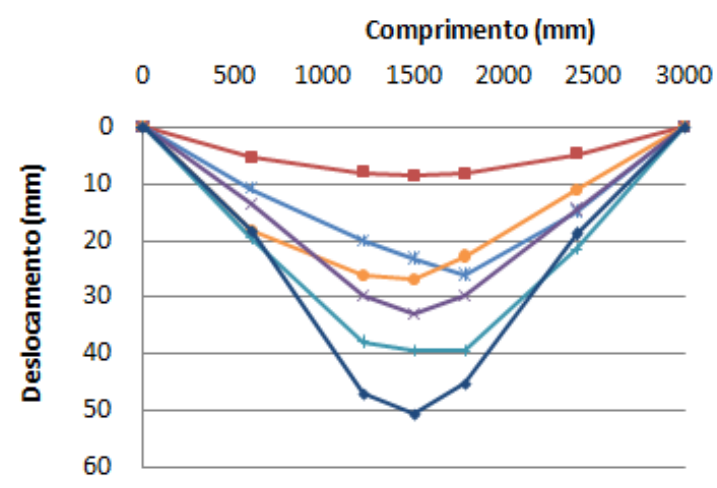

(b) Vigas com ligações parafusadas

FIGURA 13: Deslocamentos verticais de ensaio na carga de $120 \mathrm{kN}$.

\subsection{DEFORMAÇÕES ESPECÍFICAS DO AÇO}

As deformações do aço foram registradas pelos extensômetros posicionados ao longo das vigas com ligações soldadas, nas mesas e almas, deslocados $20 \mathrm{~mm}$ à esquerda das ligações. Nas vigas com ligações parafusadas, nas mesas, almas e chapas de ligações. As posições dos extensômetros não foram as mesmas para o par de vigas, soldadas e parafusadas, com emendas nas mesmas posições.

A Tabela 7 apresenta as deformações máximas obtidas nas mesas comprimidas e tracionadas em cada viga. Os extensômetros posicionados na mesa comprimida registraram deformações de compressão e os posicionados na mesa tracionada registraram deformações de tração. As Figuras 14 e 15, apresentam os gráficos Carga x Deformação de cada viga com uma ligação no meio (V1LM), soldada e parafusada, respectivamente.

Por meio dos valores das deformações máximas nas mesas em cada viga, mostrados na Tabela 7, pode-se concluir que nenhuma das vigas romperam por escoamento do aço das mesas comprimidas e tracionadas, já que as deformações máximas dos aços das vigas foram menores que a deformação no escoamento $\varepsilon_{y}$. Nenhuma das vigas com ligações soldadas romperam por escoamento do aço da alma das vigas. Pereira (2014), concluiu o mesmo em relação as vigas com ligações parafusadas. 


\begin{tabular}{|c|c|c|c|c|c|c|c|c|c|c|}
\hline \multirow[t]{3}{*}{ Viga } & \multirow{2}{*}{\multicolumn{2}{|c|}{$P_{u}(k N)$}} & \multirow{2}{*}{\multicolumn{2}{|c|}{$\varepsilon$ máx.comp. }} & \multirow{2}{*}{\multicolumn{2}{|c|}{$\varepsilon$ máx.tração }} & \multirow{2}{*}{\multicolumn{2}{|c|}{$\frac{\text { Emáx. comp. }}{\varepsilon_{y}}$}} & \multirow{2}{*}{\multicolumn{2}{|c|}{$\frac{\text { Emáx. tração }}{\varepsilon_{y}}$}} \\
\hline & & & & & & & & & & \\
\hline & Paraf. & Sold. & Paraf. & Sold. & Paraf. & Sold. & Paraf. & Sold. & Paraf. & Sold. \\
\hline VREF* & 135,0 & 160,0 & $-1,49$ & $-1,95$ & 1,45 & 1,75 & $-0,20$ & $-0,29$ & 0,19 & 0,26 \\
\hline V1LM & 135,0 & 166,0 & $-1,47$ & $-1,73$ & 1,06 & 2,3 & $-0,19$ & $-0,26$ & 0,14 & 0,35 \\
\hline V1LME & 133,5 & 160,0 & $-1,03$ & $-6,39$ & 1,08 & 3,96 & $-0,13$ & $-0,96$ & 0,14 & 0,60 \\
\hline V1LD & 138,0 & 163,0 & $-1,24$ & $-1,10$ & 3,04 & 0,66 & $-0,16$ & $-0,17$ & 0,39 & 0,10 \\
\hline V1LE & 140,0 & 175,0 & $-1,35$ & $-2,12$ & 6,94 & 1,24 & $-0,17$ & $-0,32$ & 0,89 & 0,19 \\
\hline V2L & 145,2 & 123,0 & $-1,62$ & $-0,58$ & 1,58 & 0,32 & $-0,21$ & $-0,09$ & 0,21 & 0,05 \\
\hline V3L & 126,4 & 135,0 & $-1,23$ & $-1,01$ & 1,34 & 0,88 & $-0,16$ & $-0,15$ & 0,17 & 0,13 \\
\hline
\end{tabular}

عmáx.comp. = Deformação máxima de compressão

عmáx.tração = Deformação máxima de tração

$\varepsilon_{y}$ do aço da mesa das vigas com ligações parafusadas $=7,53 \%$

$\varepsilon_{\mathrm{y}}$ do aço da mesa das vigas com ligações soldadas $=6,64 \%$ 。

* Apesar de estarem posicionadas nas colunas de vigas parafusadas e soldadas, essas vigas não tem emendas.
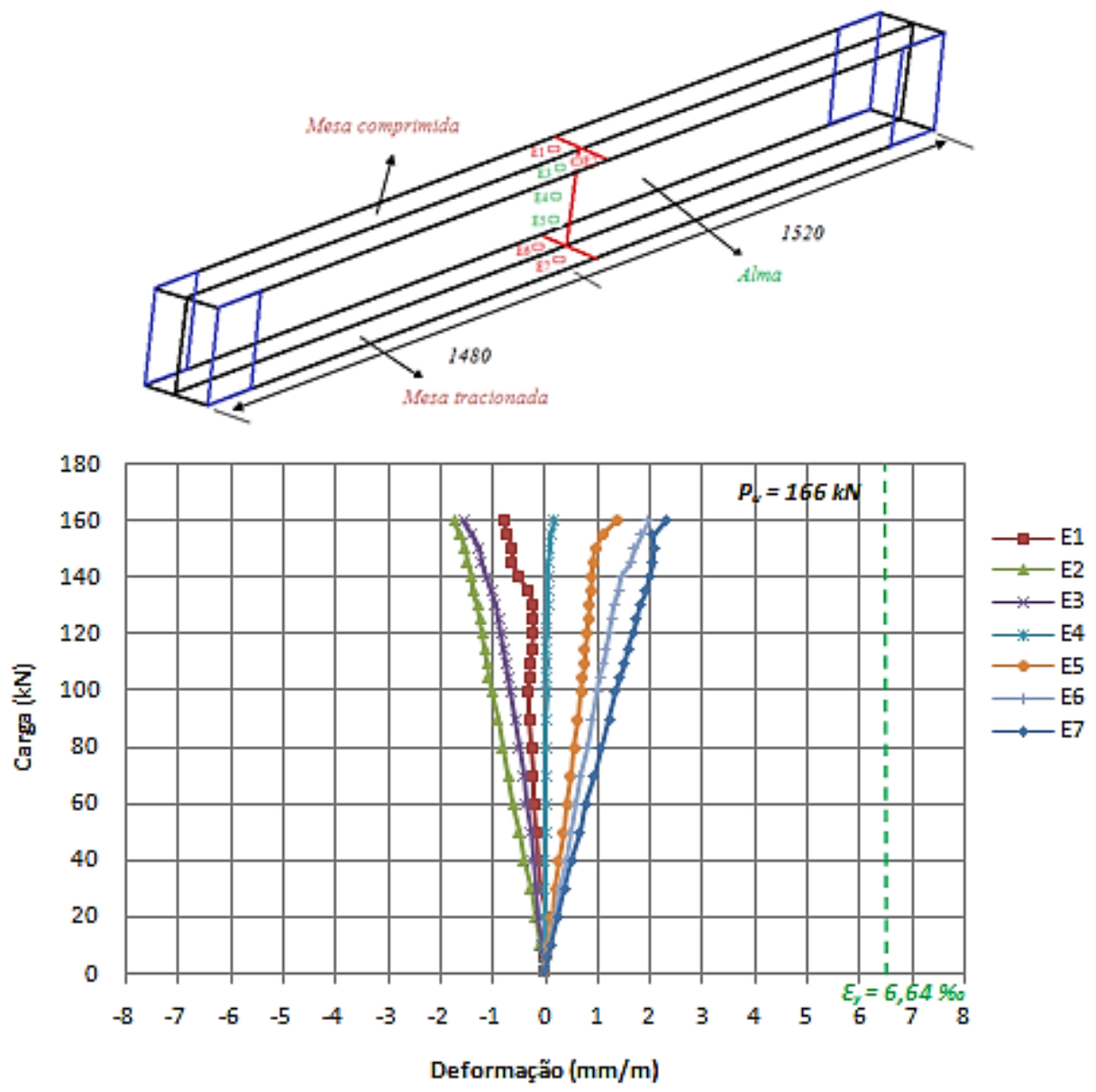

FIGURA 14: Viga V1LM soldada 

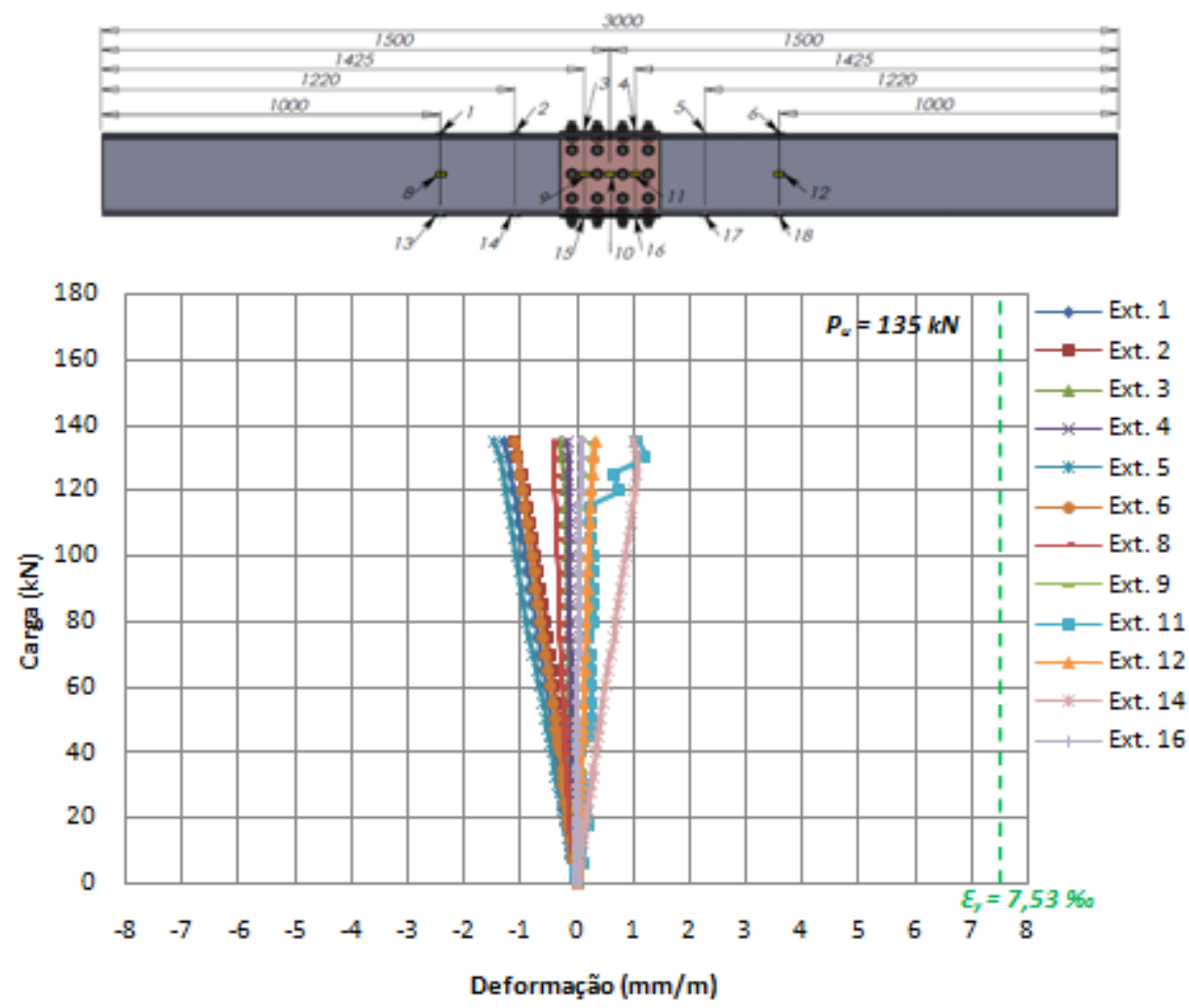

FIGURA 15: Viga V1LM parafusada.

\subsection{DESLOCAMENTOS RELATIVOS}

Nas vigas com ligações parafusadas, os LVDTs (linear variable differential transformer) foram instalados na alma da viga a $75 \mathrm{~mm}$ da extremidade da viga, em cima dos apoios de 1으 gênero e 2 o gêneros, perpendicular ao eixo de flexão da viga, com o objetivo de verificar a torção. Já nas vigas com ligações soldadas, foram instalados a $170 \mathrm{~mm}$ de cada extremidade da viga. A Figura 16 mostra a posição de cada LVDT nas vigas.

A Tabela 8 apresenta os resultados dos máximos deslocamentos lidos pelos LVDTs instalados nas vigas.

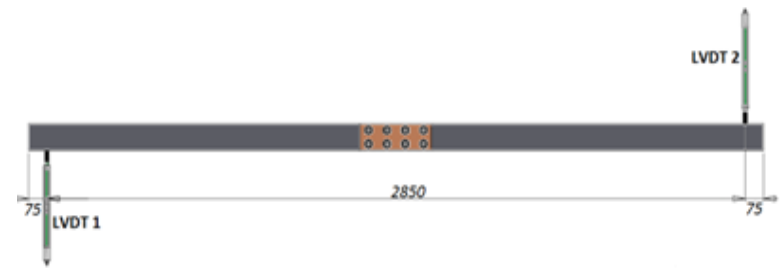

(a) Vigas com ligações parafusadas

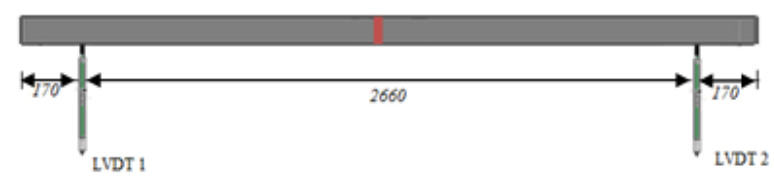

(b) Vigas com ligações soldadas

FIGURA 16: Posição dos LVDTs nas vigas. 


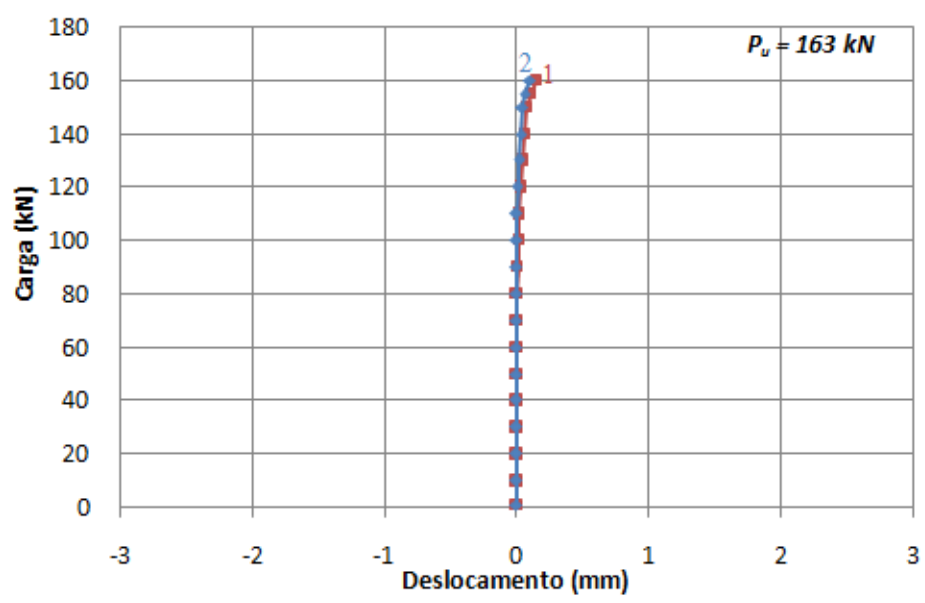

(a) Viga V1LD com ligação soldada

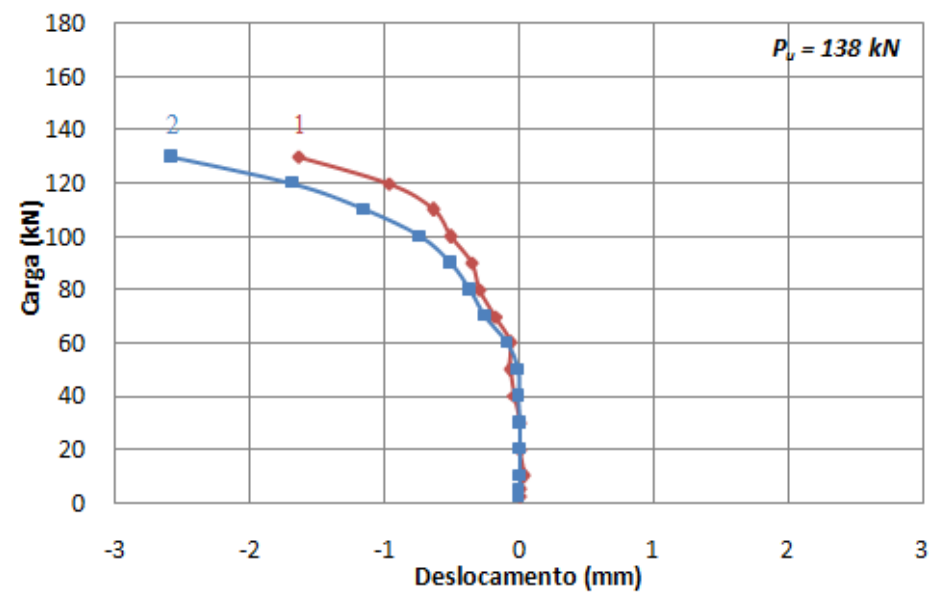

(b) Viga V1LD com ligação parafusada

FIGURA 17: Gráfico Carga x Deslocamento.

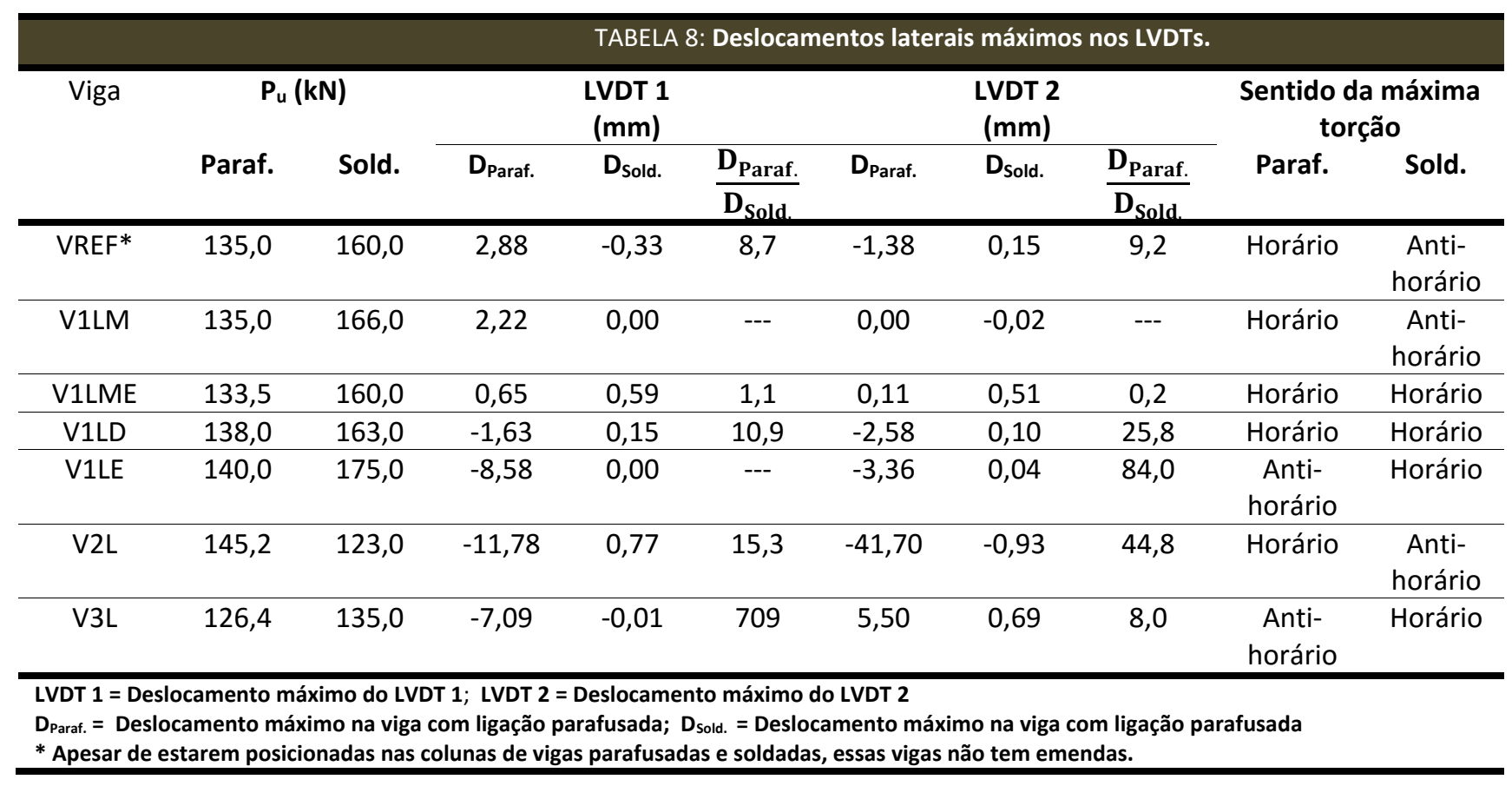


Considerando o par de vigas com ligações soldadas e parafusadas com as ligações nas mesmas posições, pode-se verificar que os resultados dos deslocamentos laterais, mostrados na Tabela 8, para as vigas com ligações parafusadas, foram muito maiores do que, praticamente, todos os resultados obtidos para as vigas com ligações soldadas. Esse fato pode ser explicado pela ausência de contenção lateral por parte das vigas com ligações parafusadas. Já nas vigas com ligações soldadas a contenção lateral nos apoios restringiu esse deslocamento lateral. A menor diferença entre os deslocamentos ocorreu entre os pares de vigas com uma ligação no meio e enrijecedores (V1LME), pois os enrijecedores restringiram o deslocamento, principalmente, da viga com ligação parafusada.

\section{CONCLUSÕES}

As ligações das vigas soldadas resistiram aos ensaios de flexão simples, não sendo constatada nenhuma ruptura nas soldas. Consideravelmente as vigas com uma ligação soldada apresentaram cargas de ruptura superiores às vigas de referência e aos valores estimados de cálculo para a carga de ruptura. Nas vigas com emendas em 2 e 3 pontos, a capacidade resistente foi inferior aquelas com emenda em apenas um ponto, pelo fato das regiões soldadas não ficarem coplanares.

A quantidade de emendas não foi um fator de colapso das vigas e nem influenciou nos seus modos de ruptura, mas a forma como essas emendas foram realizadas, pode ter influenciado no colapso antes do estimado. É preciso uma investigação melhor sobre esse fato.

A análise dos resultados dos deslocamentos laterais mostraram que as contenções laterais nos apoios desempenharam papel importante na diminuição desses deslocamentos, se comparado com os deslocamentos das vigas com ligações parafusadas.

As vigas com ligações parafusadas tiveram deslocamentos verticais de ensaios superiores aos valores teóricos de cálculo e também superiores aos das vigas com ligações soldadas, que tiveram valores teóricos e de ensaios bem próximos, provando uma maior rigidez nas vigas soldadas. Na viga parafusada, ocorreu a acomodação dos parafusos com a chapa de ligação e perfil, o que acarretou um maior deslocamento vertical. Já as deformações específicas do aço do perfil das parafusadas foram menores, pois atingiram cargas últimas menores que as soldadas.

Nenhuma viga com ligação parafusada teve carga última superior a carga última estimada de cálculo e foram inferiores a maioria dos valores encontrados nas vigas com ligações soldadas, não pelo fato de serem parafusadas, mas pela ausência de contenções laterais nos apoios que acarretou o colapso antes do esperado. Se tivesse essas contenções, possivelmente atingiria a carga última estimada, já que os valores encontrados nos ensaios ficaram bem próximos do estimado.

Todas as vigas com ligações soldadas ou parafusadas atingiram cargas superiores a 84 kN, que é a carga máxima de serviço para a viga de referência. Portanto, os resultados dos ensaios mostraram que, se bem executadas, as ligações soldadas e parafusadas, com as especificações descritas neste trabalho, podem ser utilizadas como elementos de ligações nas estruturas metálicas, pois não ocorreram rupturas desses elementos e além disso, resistiram bem aos esforços solicitados.

\section{AGRADECIMENTOS}

À Universidade Federal de Goiás, à CAPES pelo suporte financeiro, à empresa Florenzano Estruturas Metálicas pelo fornecimento da mão de obra na confecção dos modelos, ao corpo docente do CMEC pela compreensão e apoio para minha capacitação profissional, aos colegas das turmas de 2012 e 2013 do CMEC-UFG.

\section{REFERÊNCIAS BIBLIOGRÁFICAS}

ALMEIDA, A. Análise experimental de vigas constituídas de perfis formados a frio com emendas soldadas submetidas à flexão simples. 2009. 
Dissertação (Mestrado em Engenharia Civil) - Escola de Engenharia Civil, Universidade Federal de Goiás, Goiânia, 2009.

AMERICAN WELDING SOCIETY. AWS A5.18/A5.18M: Specification for carbon steel electrodes and rods for gas shielded arc welding, Miami, 2005.

ASSOCIAÇÃO BRASILEIRA DE NORMAS TÉCNICAS. NBR 8800: Projeto de estruturas de aço e de estruturas mistas de aço e concreto de edifícios. Rio de Janeiro: 2008.

ASSOCIAÇÃO BRASILEIRA DE NORMAS TÉCNICAS. NBR 7007: Aço-carbono e micro ligados para barras e perfis laminados a quente para uso estrutural. Rio de Janeiro: 2011.

ASSOCIAÇÃO BRASILEIRA DE NORMAS TÉCNICAS. NBR ISO 6892: Materiais metálicos: Ensaio de tração. Rio de Janeiro: 2013.

ASTM: AMERICAN SOCIETY FOR TESTING AND MATERIALS. Standard Specification for High-Strength Low-Alloy Columbium-Vanadium Structural Steel. ASTM A 572 / A 572M, West Conshohocken, 2006.

CARDOSO, R. S. Estudo do comportamento de vigas metálicas com seção "caixa", constituídas de perfis formados a frio, com emendas soldadas, submetidas à flexão simples. 2003. Dissertação (Mestrado em Engenharia Civil) - Escola de Engenharia Civil, Universidade Federal de Goiás, Goiânia, 2003.

PEREIRA, R. S. Ligações em estruturas de aço utilizando emendas com parafusos de alta resistência solicitadas na flexão simples. 2014. Dissertação (Mestrado em Engenharia Civil) - Escola de Engenharia Civil, Universidade Federal de Goiás, Goiânia, 2014.

SILVA, T. D. A. Estudo do comportamento de vigas metálicas em perfil soldado tipo "I", com emendas soldadas, submetidas à flexão simples. 2007 Dissertação (Mestrado em Engenharia Civil) - Escola de Engenharia Civil, Universidade Federal de Goiás, Goiânia, 2007.

VIEIRA, G. S. Análise experimental de vigas de seção I compostas de perfis formados a frio com emendas soldadas, submetidas à flexão simples. 2010 Dissertação (Mestrado em Engenharia Civil) - Escola de Engenharia Civil, Universidade Federal de Goiás, Goiânia, 2010. 